\title{
ÉTICA Y ESTÉTICA EN LA CONTEMPORANEIDAD
}

\author{
ETHICS AND AESTHETICS IN CONTEMPORANEITY
}

\author{
MiQuel Pardo \\ mpardollungarriu@ hotmail.com \\ Universidad de Barcelona
}

RECIBIDO: 14 DE JUNIO DE 2012

ACEPTADO: 11 DE AGOSTO DE 2012

\begin{abstract}
Resumen: La crisis de las sociedades contemporáneas pone en tela de juicio los valores que sostienen los vínculos entre sus miembros. A partir de un diagnóstico de la situación y de la obra de algunos filósofos y sociólogos actuales, sostenemos la tesis de que no puede haber un espacio para la ética social si no se da un tiempo para la sensibilidad estética. Nuestra reflexión aporta una vía de esclarecimiento a todo ello a partir de las paradojas de los sentimientos ajenos - aquellos que experimentamos por la acción de los otros - y de la escucha de lo inaudible: el silencio.
\end{abstract}

Palabras clave: hiperrealidad, filosofía de la música, estética fenomenológica, escucha.

\begin{abstract}
: the crisis of contemporary societies is undermining the values on which the ties between their members are based. Starting from a diagnosis of the present situation and the works of some current philosophers and sociologists, we hold the theory that there cannot be space for ethics if there is no time for aesthetic sensibility. Our reflections bring forward a way to clarify this thesis from by looking at the paradoxes associated with the feelings we experience - such as embarrassment or guilt - for other people's actions and listening to what is inaudible: silence..
\end{abstract}

Keywords: hyperreality, philosophy of music, phenomenological aesthetics, listening.

\section{Introducción}

\section{Punto de partida}

El punto de partida de esta reflexión tiene su origen en una conversación que a mediados de los 80 mantuve con un prestigioso compositor español en su época de madurez. En aquel entonces, yo era un joven compositor que empezaba su carrera artística y que quería tomar el pulso a las diversas corrientes de creación musical a través del testimonio de primera mano de uno de sus más destacados e influyentes compositores contemporáneos. La conversación, animada, había empezado al comentar diversas experiencias de este compositor a lo largo de su dilatada trayectoria - en aquel momento tendría unos 56 años de edad -, y fue, poco a poco, derivando de forma más natural hacia a la insigne figura de 
Beethoven. Fue entonces cuando él expresó una opinión de carácter más bien negativo sobre el maestro de Bonn - advierto al lector que en aquellos tiempos yo era especialmente sensible a la crítica de un artista del que siempre he sido un gran admirador, no siendo nada fácil para mí aceptar cualquier comentario contrario a este sentimiento-. Evidentemente, no me hubiese importado que la crítica hubiese sido dirigida y limitada a aspectos técnicos de la composición, dada, entre otros motivos, la distancia que nos separa en términos estéticos del clasicismo alemán. Lo que me sorprendió, e incluso me dejó en cierto estado de perplejidad y de estupor, fue que su crítica iba orientada a desacreditar el posicionamiento ético de Beethoven y más concretamente contra el homenaje que Beethoven que ofrece a la fraternidad universal, expresada de manera magistral y colosal en su Sinfonía $n^{o} 9$ en Re menor opus 125, "Coral" probablemente una de sus obras más conocidas por al gran público -.

¿Qué podía haber de ofensivo, me preguntaba, en el carácter ético del compositor alemán para motivar el malestar de un compositor actual? Lo cierto es que para mí, - y no sólo entonces sino también ahora - , la sombra de Beethoven - aparte de proyectarse gigantesca sobre la historia universal de la música y de ser una cima inexpugnable para los compositores que le siguieron es el paradigma de la actitud ética para cualquier artista.

Como es de todos sabido, con 28 años, Beethoven fue perdiendo audición progresivamente, circunstancia esta que le afectó a su carácter y a la relación con sus congéneres de modo determinante. Por las fechas de la composición de su IX , el compositor alemán acabó prácticamente sordo y el medio para hacerse entender era escribir en libretas de las que se conservan un buen número. Paradójicamente, sin embargo, es en esta última etapa de su vida que escribe la música más interesante, más evolucionada y más trascendente de su trayectoria artística. Es la época de sus últimas sonatas para piano, de las Variaciones "Diabelli", de sus últimos cuartetos, de la Misa Solemnis y la Sinfonía ${ }^{o}$ 9, "Coral". Frente a este trabajo ingente, de esta monumental aportación al arte universal, uno se pregunta "por qué". ¿Qué podía motivar a Beethoven a donar como legado a la humanidad una música excepcional, padeciendo un estado de sordera que le impedía inexorablemente el disfrute de oír su propia música?

Lo cierto es que ha habido, a lo largo de la historia, compositores ciegos que han escrito música - el mismo J. S. Bach tuvo que "dictar" su Arte de la fuga a su yerno, debido a la ceguera que le acompañó en su vejez -, incluso ha habido excelentes compositores ciegos de nacimiento. Para un músico, la ceguera no le impide el ejercicio de sus aptitudes creativas, hasta el punto que incluso podríamos estimar positivamente el beneficio que puede suponer para la atención y la concentración necesarias para su actividad, puesto que no es estorbado por ningún tipo de estímulos visuales. Sin embargo, nunca se ha tenido noticia, por 
ejemplo, de la existencia de un pintor ciego: sería algo extrañísimo, por no decir imposible, que un pintor trasladase a una tela una imagen que él mismo no pudiera contemplar con sus propios ojos. Análogamente, Beethoven hubiera podido disfrutar de su música "silenciosamente" desde el ejercicio intensificado de su imaginación y nadie por ello osaría reprochárselo. No sólo no hizo eso, sino que llegó a escribir el estallido musical más apoteósico de alegría que nunca se ha escrito, así como la mayor afirmación de fe absoluta en la humanidad y de la fraternidad universales desde la soledad más profunda que pueda llegar a sentir un músico o un artista en general: ésta es, sin duda, la mejor muestra de una grandeza de espíritu que supera toda comparación.

¿Qué puede haber, entonces, en la sensibilidad contemporánea para que un artista actual llegue a valorar como algo perverso y negativo la expresión de la fraternidad universal?

Los valores éticos I: los ideales de la Ilustración y del clasicismo vienés.

"Liberté, egalité, fraternité" eran las consignas de la Revolución francesa y los ideales de la Ilustración, encarnados perfectamente en la trayectoria no sólo artística sino vital de Beethoven.

Libertad: Con el genio de Bonn, el compositor empezó a dejar de ser de ser un simple "criado" - no muy lejos de un lacayo culto, más o menos bien considerado por el aristócrata-mecenas de turno o por un príncipe de la Iglesia -. El músico puede ahora sobrevivir de los recitales que ofrece a un público no necesariamente aristócrata - surgen en aquel entonces los primeros locales de entrada pública, principalmente destinada a la burguesía en alza -, componiendo por encargo y publicando sus obras para su difusión.

Igualdad: Beethoven no aceptaba la desigualdad por nacimiento. Frente a la "nobleza de sangre", alegaba una "nobleza de espíritu": "Lo que usted es escribía Beethoven en una nota dirigida al príncipe Lichnowski, uno de sus mecenas y admiradores más fieles- lo es por accidente de nacimiento; lo que yo soy, lo soy por mi mismo. Hay y habrá miles de príncipes; hay un único Beethoven"1. Contrariamente a la actitud prepotente del "propietario de terrenos" - haciendo alusión a una carta de su hermano Karl - Ludwig se sentía "propietario de un cerebro" 2 .

\footnotetext{
${ }^{1}$ Kerst, Friedrich: Beethoven: the Man and the Artist, as Revealed in his own Words, H.Krehbiel (Editor), disponible on-line en www.gutenberg.org/ebooks/3528. Pág. 47 (último acceso 30 de julio 2012)

${ }^{2}$ Scott, Marion M.: Beethoven, Salvat editores, Barcelona, 1985. Pág. 99
} 
Fraternidad: Beethoven da testimonio de un amor profundo no sólo a sus amigos, sino a la humanidad entera, como hemos apuntado anteriormente.

No obstante, su militancia en estos ideales no le protegió de grandes decepciones en el terreno biográfico. La primera de ellas la encontramos en la composición de la Sinfonía $n^{o} 3$ en Mi b, "Heroica", dedicada en un principio a la memoria de Napoleón Bonaparte, del "grand' uomo" en el que el compositor alemán veía realizadas sus esperanzas revolucionarias más profundas y la culminación de sus ideales en todo el orbe. La barbarie de las tropas napoleónicas en la campaña austríaca fue suficiente para demostrar el talante de este personaje: un miserable oportunista y un déspota más de la larga lista que nos provee de vez en cuando la historia.

"Muss Es sein? Es muss sein! Es muss sein!" - “¿Debe ser? ¡Debe ser! ¡Debe ser! -. Con estas palabras escritas al inicio del tema principal comienza el "Grave ma non troppo tratto" del cuarteto opus $135^{3}$. De este modo, Beethoven acepta la muerte cercana, como en su día aceptó su sordera, y como también lo hace con el fracaso de sus ideales revolucionarios. Sumido en la soledad de su soltería, sin familia, consagrado exclusivamente al arte e incomprendido por sus coetáneos, ¿dónde queda ahora la igualdad tan apreciada, al contemplar al genio de Bonn envejecido, enfermo y aislado del mundo por su sordera? - ¡hoy en día hablaríamos de él como de un discapacitado físico! ¿Pero qué igualdad podía reivindicar en aquellos tiempos un discapacitado? -.

Tampoco dejó de pagar caro su ideal de fraternidad: después de luchar y finalmente conseguir la custodia legal de su sobrino Karl - hijo de su hermano fallecido -, la relación con éste lo inutilizó artísticamente durante casi una década. Y a pesar de ello, su obra respira una paz, una gratitud hacia la vida, que la transfigura en una empresa sobrehumana.

\section{Los valores éticos II: la crisis del concepto de fraternidad}

Desde el momento que emigramos del mundo gobernado por la Providencia que tan bien supo construir san Agustín - y nos adentramos en la modernidad agnóstica y científica, el concepto de fraternidad queda de alguna manera herido de muerte. La Providencia es el Padre de quién toda la humanidad creyente se siente hijo adoptivo. El hombre de fe se concibe como hijo en el Hijo, hermanado espiritualmente con el resto de los fieles. Con el cambio a la modernidad, este tipo de sentimiento deja de tener un fundamento teológico, para pasar a ser más humanístico, menos celestial. La pertenencia a una patria común

\footnotetext{
${ }^{3}$ Beethoven, Ludwig van: Complete String Quartets, Dover Publications Inc., New York, 1970. Pág.201
} 
- "Allons, enfants de la Patrie!", comienza el himno revolucionario francés-, a un gremio, a una co-fradía profesional o militar se convierten en vínculos asimilados a los de sangre. A pesar del catolicismo practicante y explícito de Beethoven - consideraba a su Missa Solemnis como su obra más importante (por cierto, obra "hermana" en el tiempo de la IX ${ }^{a}$ Sinfonía) -, el concepto de fraternidad que yace en el texto de Schiller es propiamente moderno ${ }^{4}$.

Será en la fase nihilista y atea de la época de la revolución industrial, especialmente ejemplarizada en la filosofía de Nietzsche - aunque también de algún modo en la ciencia darwiniana - donde hallaremos, sino un ataque frontal, al menos un cuestionamiento radical de la idea de fraternidad: en el primero, su "olfato de psicólogo" detectará cierto "tufo a establo" insoportable para un espíritu aristocrático; en el último, más allá del origen común de nuestra especie, se desvelará en el sentimiento de fraternidad una contrariedad para la tesisi de la supervivencia del más apto.

Tampoco la lucha de clases, ni la libre competencia de mercado, considerarán la fraternidad universal como un factor dinamizador de las revoluciones sociales que contemplará el siglo XX, más allá de la mera coincidencia grupal de intereses individuales. A pesar de todo, emergerá de les cenizas de la vieja fraternidad un concepto nuevo, más ligado a la praxis social que al sentimiento individual: el concepto de solidaridad.

\section{Los valores éticos III: algunos apuntes redefinidores}

La libertad se ha venido entendiendo a partir de la modernidad como un derecho inalienable de todo individuo y toda nación; y la carta de los derechos humanos es la materialización en un solo documento de este criterio. Pero la realidad nos dice que andamos muy lejos de que estos derechos lleguen a ser efectivos y plenamente operantes. Todo lo contrario: jamás como en nuestros días se han visto nunca tan vulnerados en la práctica ${ }^{5}$.

El arte, sin embargo, nos enseña otra cara de la libertad: la libertad entendida no como un derecho sino como una semilla que hay que cultivar para que madure.

\footnotetext{
4 Sobre las connotaciones religiosas que sin duda podemos detectar en los ideals revolucionarios ilustrados, es necesario tener en cuenta el papel tan decisivo de la masoneria europea y norteamericana.

${ }^{5}$ No sólo son vulnerados abiertamente en los regímenes dictatoriales, sinó de una manera más sutil y sibilina en las democracias occidentales. La crisis económica que padecen gran parte de los países europeos (entre ellos, el nuestro) ha puesto de manifiesto como el estado del bienestar y los derechos de los ciudadanos son pisoteados de forma arbitraria por el poder fáctico financiero, ante la impotencia, cuando no la colaboración, de los gobiernos y de los representantes políticos democráticamente elegidos.
} 
Su modelo es la libertad del maestro, del artista, a diferencia del torpe capricho del aprendiz o del diletante, que, aunque pueda tener una engañosa apariencia de libertad, en realidad queda muy lejos de lograrla. Es preciso, pues, distinguir entre libertad y la simple no-esclavitud.

Así, la falta de libertad auténtica lleva como resultado a un incremento del orden represor, del control sobre cada individuo. No obstante, libertad y orden no son términos opuestos: son los ingredientes básicos para tener una actitud responsable. En este sentido, podemos detectar la insinuación de una cierta perversión moral en el dualismo comúnmente aceptado entre "régimen de orden"/"anarquía caótica", lo cual expresa, a nuestro parecer, un miedo escondido a la libertad y un odio irracional al orden. En el ámbito artístico, ello se vería reflejado en la sensación de pánico ante la hoja en blanco, o en la incapacidad de elegir entre varias opciones por miedo a perder hipoptéticas oportunidades.

La igualdad, en cambio, sí que se la puede considerar un derecho: el derecho a ser tratado como un igual en lo básico y universal al resto de personas, en tanto reconocimiento de un principio común y compartido. Queda esto muy bien expresado en los sistemas meritocráticos como principio de igualdad de oportunidades, que, en el caso de que fuera aplicable a cada individuo en particular, conduciría a la disolución de los privilegios de clase, a menudo basados en la propiedad y en la transmisión de bienes hereditarios. Por cierto, un reto para la sociedad consistiría en poder hacer compatibles la meritocracia individual en el momento presente y el fruto del mérito legado por los antepasados en herencia.

Entre los filósofos contemporáneos, Derrida utilizará la noción de différance contra la tiranía de la igualdad, ${ }^{6}$ entendida ésta como homogenización en una linealidad discursiva de significado. En este sentido, la igualdadhomogeneidad vendría a oponerse también a la diferenciación-especialización con la que Durkheim caracteriza la modernidad. ${ }^{7}$ Detectamos así una tensión dialéctica entre la igualdad superadora de la diferenciación moderna (igualdad "positiva") y la igualdad como factor difuminador de los perfiles de los objetos y

\footnotetext{
${ }^{6}$ Derrida, Jacques: La différance, Bulletin de la Societé française de philosophie (julio-septiembre, 1968), disponible on-line en www.jacquesderrida.com.ar/textos/la_differance.htm. Como señala Lyon, David: Posmodernidad, Alianza Editorial, Madrid, 1996, Pág 39 : " Derrida defiende la différance contra la tiranía de la igualdad y trata de deconstruir la dicotomía masculino-femenino".

${ }^{7}$ Durkheim, Émile: La división del trabajo social, Ediciones Akal. Madrid, 1987 y en El suicidio. Ediciones Akal, Madrid, 1982. En esta última, Durkheim define la anomia como el mal que castiga a una sociedad que carece de reglas morales y de su expresión en la falta de normas jurídicas. Véase también la referencia a la "diferenciación" y a la "anomia" de Lyon, David en Opus cit., Pág 52 y Pág 62-63.
} 
relativizador de significados (igualdad "negativa") - sirva de ejemplo el debate sumamente complejo sobre la igualdad de la mujer respecto del hombre en los diversos enfoques que se han dado en el feminismo.

El sentimiento que despierta la igualdad en sentido positivo es el del amor a lo común y a los individuos que lo comparten, a la comunidad. Por el contrario, el sentimiento opuesto al que genera la igualdad es el que lleva a la discriminación en sus múltiples formas.

Finalmente, la fraternidad no es propiamente ni un derecho ni un deber, sino que tiene que ver más con la conciencia de unidad que se establece entre los diversos miembros de una comunidad. La fraternidad universal significa, pues, llegar a aceptar la unidad entre todos los individuos y todos los pueblos del mundo. De esta manera, la fraternidad actúa como un punto de equilibrio entre la libertad que yo tengo y la que veo en el otro, más allá del sentido de igualdad, en cuanto que amo la diferencia entre ambos. El amor a lo común, propio del sentido de igualdad se transforma en hermandad en el momento que logramos asumir la libertad propia conjuntamente con la del otro: somos alguien en la medida que ejercitemos nuestra libertad. Mientras que la igualdad mira al pasado, al origen común, y la libertad se proyecta al futuro en cuanto a su realización, la fraternidad es el reencuentro final de todo este despliegue que retorna a si mismo.

Por eso, la ausencia o carencia de este sentido de unidad presente en la fraternidad genera lo que entendemos por extrañeza. Simmel, y anteriormente Baudelaire con su personaje el flâneur, describen una sociedad de extraños basada en relaciones contractuales, meramente formales, ${ }^{8}$ lo cual conduce finalmente a una fragmentación social donde los individuos quedan aislados entre si, provocando la pérdida de valores como la solidaridad o la fraternidad. Podríamos hablar en este caso de un problema de tiempo y de espacio sociales. La distancia, la ausencia de un espacio de relación - el "cara a cara" personal también afectará a la conducta moral: la distancia física nos insensibiliza de las calamidades de la guerra en el otro extremo del mundo, mientras que la distancia racial nos deja en un estado de indiferencia para las injusticias que padecen aquellos que no se parecen a nosotros.

\footnotetext{
8 "El reconocimiento de lo fugaz, de lo transitorio, de lo superficial es el precio que hay que pagar para comprender qué es la modernidad. El flâneur se hallaba en una posición prvilegiada, dijo Simmel, precisamente porque era anónimo. Era un extraño entre extraños”. Lyon, David, Op. cit., Pág.66.
} 


\section{Tesis}

Los problemas de índole ética en la actualidad - violencia de género, terrorismo, ausencia de valores morales, etc. - no son originariamente autónomos, sino que tienen una raíz estética: el comportamiento general de los individuos responde a una experiencia estética común a la sociedad y que actúa generalmente de manera subliminal, a oscuras, y que los artistas manifiestan o bien denuncian de forma transparente en sus obras. En síntesis: no puede haber "espacio" para una ética - en el sentido de un marco para una acción íntegra individual proyectada al exterior - si no hay "tiempo" para una estética.

La estética subyacente a nuestra contemporaneidad, en tanto que percepción sensible de la realidad, sin tiempo - sólo el tiempo dado para la gestión, el de los horarios de oficina, de la planificación industrial, incluso del ocio, etc. -, o mejor dicho, sin tiempo de calidad, queda ejemplificada en el "zapping", es decir, en la actitud de instalarnos en una virtualidad vacía de contenido, alimentada por un control de la situación - gráficamente ilustrada por el "mando a distancia" de un electrodoméstico - que se satisface en su posibilidad "en sí", en tanto que nunca puede llegar al nivel de concreción esperable, so pena de perderla.

La preocupación sobre la importancia del tiempo no es nueva. Ya en Kant el tiempo es concebido como condición necesaria de posibilidad para el pensamiento. ${ }^{9}$ Por eso, sin tiempo no es posible hacer filosofía. Sin embargo, avanzamos al lector que será la conexión que estableceremos entre la noción de tiempo de "calidad" y el tempo musical lo que iluminará su sentido profundo.

\section{La ética en tiempos de crisis}

En una primera etapa, el individuo es presionado por una ideología dominante que fagocita todos aquellos bienes exteriores que la naturaleza nos da "gratuitamente" (agua, aire, espacio vital, alimento...); pero posteriormente y de forma imparable esta ideología invade también el marco y el ámbito de nuestra interioridad y subjetividad: la falta de tiempo, no sólo en un sentido meramente cronológico, sino como un tiempo necesario, el tiempo que "piden las cosas", incapacita al individuo a reaccionar como un todo, íntegramente, como "habitante", en el sentido heideggeriano del término, de un espacio interior. En

\footnotetext{
${ }^{9}$ Recogido por Adorno, segun el cual "Kant observa que incluso el puro acto de pensar implica el transcurrir de la serie temporal como condición necesaria de posibilidad, y no solamente de la realización empírica del acto". Adorno, Theodor W.: Musikalische Schriften III, vol. 16, Suhrkamp Verlag, Francfort del Meno, 1978. Hay traducción al español por Paidós, Barcelona, 2000, con el título Sobre Música, Pág. 45
} 
consecuencia, la percepción estética queda reducida exclusivamente a una sensibilidad refleja sin tiempo a que llegue a los centros nerviosos superiores, al cortex cerebral; una sensibilidad que podríamos calificar de "amébica", de una simplicidad más propia de un protozoo que de un ser humano. Una sensibilidad así sólo puede responder a los mecanismos elementales de pura supervivencia individual, a modo de un egocentrismo "biológico", que es incapaz de articular una perspectiva del mundo más allá de una pura compulsión neurofisiológica.

El diagnóstico de la ética contemporánea no debería estar basado - como así se ha hecho tradicionalmente -, en la autonomía de su propio campo paradigmáticamente fundamentado en el imperativo categórico kantiano -. No se trata aquí de una "pérdida de las buenas costumbres" o de una relajación de éstas por motivos culturales o socio-económicos, sino de la imposibilidad ontológica de toda ética, o, dicho en otras palabras, de la inexistencia hoy en día de unes condiciones de posibilidad para una ética social.

Muy lejos queda la visión esperanzada de Georg Simmel cuando llegó a afirmar que en tiempos de incertidumbre y confusión se produce un retorno a la estética e incluso un sentido de moralidad en el arte. ${ }^{10} \mathrm{~A}$ pesar de que reconozcamos en la reflexión de Simmel la estrecha conexión que existe entre los dos ámbitos, constatamos que, precisamente por este motivo, la resolución de esta problemática no es en absoluto sencilla. En este orden de cosas, también Gianni Vattimo apuesta por una reconciliación ${ }^{11}$ - una "Verwindung" como apuntaría Heidegger ${ }^{-12}$. Pero en este caso la cuestión radicaría en como puede un individuo sometido a la fragmentación y a la diferenciación, a la alienación y al desarraigo de su ser, sacar fuerzas del puro anonadamiento y reencontrar la dirección adecuada.

Algunos pensadores analizan las cosas de otro modo. Foucault ve al hombre "muerto" - en el sentido opuesto al de ser consciente, activo, "vivo" ${ }^{13}$-, condenado a ser prisionero y a la vez cómplice del mismo poder que lo mata, sin la seguridad y confianza en la reacción espontánea de un cuerpo-mente fisiológicamente sanos y un instinto aún no suficientemente estropeado. El atrincherarse en el argot - la "jerga" al uso- y en el tecnicismo estéril no es más que un síntoma palpable del miedo a "vivir", no en el sentido agradable y acomodaticio de "bienestar" que nos procura el sistema, sino desde la asunción de la pérdida, del dolor y finalmente de la muerte. ${ }^{14}$

\footnotetext{
${ }^{10}$ Lyon, David: Op. cit., Pág 33

${ }^{11}$ Vattimo, Gianni: El fin de la modernidad. Gedisa, Barcelona, 1986. Pág. 4

${ }^{12}$ Lyon, David: Op. cit., p. 31

${ }^{13}$ Lash, Scott: Sociology of Postmodernism, Routledge, London, New York, 1990, Pág. 55

${ }^{14}$ Algo similar sucede en la música contemporánea por parte del público, cuyo sentido vivencial parece haberse perdido. Así, en general se prefiere asistir a una conferencia que trate sobre música
} 
Baudrillard, que nos invita a olvidar a Foucault, es un autor mucho más consciente del papel que juegan los llamados "medios de comunicación de masas" sobre la vida de los individuos. ${ }^{15}$ El dominio, el control, el auténtico poder, lo detentan las imágenes en la pantalla, sometidas a un proceso minucioso de montaje, a una misse en scène, que condiciona y determina nuestra comprensión de la realidad; lo cual potencia la carga simbólica de cualquier evento o acción humanos: el consumo como intercambio simbólico, el terrorismo como violencia simbólica, etc..

Según Baudrillard, vivimos en una hiperrealidad hecha de simulacros autorreferenciales, en donde quedan difuminadas las fronteras entre los objetos reales y su representación 16 - un "mundo fantasmagórico", según Walter Benjamin -. La realidad virtual suplanta así a la realidad entendida desde una actitud natural, puesto que la simulación no es experimentada como algo falso o fingido, sino plenamente coherente; y dentro de los dominios de esta coherencia todo juicio moral queda automáticamente relativizado. El pánico, también moral, que describe Baudrillard, ${ }^{17}$ como el sentimiento básico en el hombre o mujer actuales - y que coincide, más allá de la burda repulsa, también con el estado afectivo que genera en el espectador gran parte del arte contemporáneo -, ¿qué es sino una psicosomatización vivida histéricamente de esta identidad fragmentada del propio individuo?

Tampoco parece haber salida de este callejón para aquellos autores que centran todo sentido en el marco exclusivo del lenguaje, sea éste hablado o escrito, como en el caso de Derrida. ${ }^{18}$ La pérdida acelerada de los hábitos de lectura de las nuevas generaciones de jóvenes en beneficio del control sobre los nuevos artefactos audiovisuales los arroja irremisiblemente a la agonía de todo significado por falta de tiempo para acceder al lenguaje. ${ }^{19}$ Incluso la incredulidad en relación a los récits, a las meta-narraciones, que describe Jean-François Lyotard ${ }^{20}$ podría, en mi opinión, compartir una raíz común con la problemática de los simulacros que apuntaba Baudrillard, en el momento en que nuestra percepción estética queda confinada exclusivamente a les "epopeyas" de celuloide que cada vez con más frecuencia inundan las pantallas de los cines y de

\footnotetext{
contemporanea que asistir directamente a un concierto para escucharla.

${ }^{15}$ Baudrillard, Jean: Olvidar a Foucault, Pre-textos, Valencia, 1986

${ }^{16}$ Lyon, David: Op. cit., Pág. 93-94

${ }^{17}$ Ibid., Pág. 140

${ }^{18}$ Ibid, Pág. 38

${ }^{19}$ El problema que yo mismo, a menudo, constato como docente ya no radica, a mi parecer, exclusivamente en el nivel de preparación o en el bagaje de cultural general de los alumnos, sino de su incapacidad manifiesta de comprensión, no ya de vocabulario, sino - lo que es más grave - de las mismas estructuras sintácticas.

${ }^{20}$ Lyotard, Jean-François: La condición posmoderna, Cátedra, Madrid, 1989, Pág. 24
} 
los televisores. El "collage" formado por los astros y estrellas de Hollywood o de cualquier otra de sus sucursales, encarnando ayer a un héroe de la tragedia de un transatlántico hundido, hoy a las peripecias de un aprendiz de mago y mañana la de un semidiós homérico con las actitudes de un oriundo de Oklahoma, parece ser la única posibilidad de discurso y de modelo estilístico para la postmodernidad.

\section{La fuerza del símbolo}

En una conferencia pronunciada en l'Institut du monde arabe, Jean Baudrillard hizo una interpretación del acontecimiento del 11-S a partir de la simbología que se desprendía de las torres gemelas: ${ }^{21}$ las torres del WTC eran monolitos ciegos, cerrados al exterior, sin rostro, como dos cajas negras, como dos sarcófagos de hormigón y acero, en los que la arquitectura, a imagen del sistema, sólo emana de la clonación. Baudrillard percibe una violencia de carácter estético, arquitectónico, en que el horror de morir dentro de estos edificios es inseparable del horror de vivir y trabajar ahí. Viéndolas como se desplomaban, se tenía la sensación de contemplar un suicidio de las mismas torres. Así, para al sociólogo francés, el desplome simbólico fue el verdadero causante del desplome físico, y no al revés - de hecho, según parece, ni los propios terroristas habían previsto la posibilidad de la caída de las torres -.

Cansadas de su peso simbólico, las torres se hunden convirtiéndose en cómplices de su propia destrucción: "la mayoría de las cosas no son dignas de ser destruidas o sacrificadas. Solamente las obras de prestigio merecen serlo, porque es un honor", ${ }^{22}$ escribe Baudrillard - frase que me recuerda mucho a la opinión del compositor contemporáneo alemán Helmut Lachenmann, en relación a la superioridad de la belleza "destruida" sobre la belleza "inmaculada" -. "Sólo debería ser construido lo que por su excelencia sea digno de ser destruido", ${ }^{23}$ continua el sociólogo francés. El razonamiento de Baudrillard es sumamente inquietante: "Si eludimos aquel momento de estupor, de "admiración" - inmoral, es cierto, pero que condensa, a través de la inmoralidad de la imagen, la intuición extraordinaria del acontecimiento - si rechazamos aquel momento, perdemos toda posibilidad de comprender". ${ }^{24}$

He aquí una interpretación basada exclusivamente en el aspecto estético de una acción horripilantemente inhumana. Por el contrario, frente al holocausto

\footnotetext{
${ }^{21}$ Baudrillard, Jean: La violencia del mundo, Paidos, Barcelona, 2004

${ }^{22}$ Baudrillard, Jean: La violencia del mundo. Paidós, Barcelona, 2004, Pág. 20

${ }^{23}$ Ibid. , Pág. 21

${ }^{24}$ Ibid. , Pág. 22
} 
"mediático" yo personalmente siento un profundo pudor que bloquea mi comprensión: la primera emoción que me inunda es la de un horror inefable y no, como señala Baudrillard, de admiración. La sensación estética que experimenta Baudrillard está, a mí entender, condicionada por la inmediatez del tiempo "real" mediático y, por lo tanto, es superficial, fantasmagórica: por eso no llega a producir un verdadero juicio moral.

Normalmente, el consumo repetido de imágenes agota el acontecimiento por delegación, lo que convierte la imagen en una especie de refugio, actuando como un conjuro contra el crudo acontecimiento. En el caso del WTC el trauma producido ha convertido la imagen misma en puro evento. Como reconoce Baudrillard, el acontecimiento es en si irrepresentable para el discurso interpretativo. Estamos, pues, frente a una singularidad que detiene brutalmente la imagen y con ella, toda posibilidad de discurso.

Nuestro sociólogo asegura que un incremento de violencia no es suficiente para abrirnos a la realidad. Así, su interpretación "mass mediática" nos ofrece una perspectiva en la que la realidad como principio se ha perdido: lo real se añade a la imagen, y no al revés, como "prima" de terror, como un estremecimiento más - diríamos pues que no sólo es terrorífico, sino que ¡Además, es real! -. Solamente la violencia simbólica - concepto clave también para otro gran sociólogo francés, Pierre Bourdieu ${ }^{25}$ - genera singularidad. Reales o eventuales, la inmensa mayoría de las cosas no constituyen acontecimientos, sino que son del orden de la continuidad. Hay, pues, una clara distinción entre la eventualidad - posible imaginado - del evento - en si imprevisible - ${ }^{26}$ En este sentido todo acontecimiento digno de este nombre es, en cuanto que rompe con la continuidad, terrorista (!). En consecuencia, los atentados del 11-S no deberían interpretar la irrupción de lo real, sino de lo simbólico.

¿De qué naturaleza es, pues, este símbolo tan potente que irrumpe aquí tan brutalmente? Para Baudrillard, es la imposibilidad de intercambio de la muerte. ${ }^{27}$ Por eso, el mensaje secreto del terrorismo es, a través del suicidio, el intercambio imposible; el desafío al sistema mediante el don simbólico de la muerte, que es el arma absoluta. Lo que indirectamente significa también la ratificación de la muerte de la política y del Estado. Para la lógica del sistema, basada sobre un mundo saturado de sentido, finalidad y eficacia, el terrorismo no tiene ni sentido ni objetivo; y ello se debe a que el terrorismo desplaza la lucha a la esfera simbólica. De este modo descubrimos que el objetivo del terrorismo es que el

\footnotetext{
${ }^{25}$ Bourdieu, Pierre: La distinción, Taurus, Madrid, 1998.

${ }^{26} \mathrm{Sin}$ duda, podemos aquí detectar un puente de similitudes entre la fenomenología de MerleauPonty y el tiempo mesiánico de Walter Benjamin en el pensamiento del sociólogo francés: el acontecimiento es del orden de la discontinuidad y de su ruptura.

${ }^{27}$ Baudrillard, Jean: Opus cit. Pág. 29
} 
sistema se suicide como respuesta al desafío múltiple de la muerte y el suicidio, puesto que ni el sistema ni el poder pueden escapar a la obligación simbólica de responder so pena de perder el rostro.

Sin embargo, el terror no es una alternativa al sistema. Es la pura desesperación frente al pensamiento único dominante. El terrorismo es, para Baudrillard, el acto que restituye una singularidad irreductible en el corazón de un sistema de intercambio generalizado ${ }^{28}$ - un sistema en el que todo y todos tienen un precio -. Sin embargo, se equivoca Braudillard, a mi entender, al interpretar el suicidio de los terroristas como un objeto no intercambiable. La eutanasia activa o incluso determinados prácticas sexuales sado-masoquistas que conducen hasta el asesinato, difundido a todo el mundo a través de internet, se pueden tomar como ejemplos de la existencia de un "negocio lucrativo de la muerte" dentro del sistema.

No. Lo que es realmente inintercambiable es el absurdo, la irrupción de lo irracional en nombre de un símbolo determinado. Esto siempre ha estado presente en casos particulares de individuos desesperados que sólo ven una salida en el crimen o en el suicidio - y, muy a menudo, en la combinación de ambos -. Lo que resulta novedoso es la esmerada organización y planificación de toda esta desesperación en colectivos más o menos numerosos.

\section{Pensar la crisis}

Las crisis no deberían ser un concepto teñido de connotaciones negativas. Krisis, en griego, significa aquello que permite hacer un diagnóstico. Ahora bien, se da por sobreentendido que el observador que diagnostica la crisis no se encuentra el mismo o sus instrumentos de observación en un estado afectado o padeciendo tal crisis, dado que esto perturbaría sensiblemente la objetivudad de su diagnóstico. Sin embargo, el pensamiento contemporáneo está en crisis permanente. La pregunta surge necesariamente: ¿está capacitado el pensamiento en crisis para pensar la crisis sin verse arrojado irremisiblemente al error?

Edgar Morin, uno de los autores que más han reflexionado sobre los problemas sociales actuales, analiza la sociedad capitalista actual. ${ }^{29} \mathrm{La}$ ley anónima de la mercadería tiende siempre a aniquilar todas las relaciones humanas caracterizadas por la gratuidad. He aquí un término que se escapa, como diría Baudrillard, del intercambio. Al carácter gratuito de los sentimientos se podría asociar su poder simbólico: por eso, la injusticia más grave no es la

\footnotetext{
${ }^{28}$ Ibid. Pág .41

${ }^{29}$ L'Yvonnet, François, Prólogo a Morin, Edgar: En el corazón de la crisis planetaria, Paidós, Barcelona, 2004. Pág. 45
} 
material, sino la moral. El filósofo francés constata la existencia de un subdesarrollo psicológico y moral palpable en las sociedades occidentales: " El desarrollo, con su carácter fundamentalmente técnico y económico, ignora todo lo que no sea calculable, medible, como la vida, el sufrimiento, la alegría, etc. Pasa por alto riquezas humanas no calculables, como la generosidad, los actos gratuitos, el honor, la conciencia". ${ }^{30}$ Sin embargo, tanto el "mito" del progreso ilimitado, como la convicción de ser dueños de la razón, no son nada más que ilusiones irracionales.

Si bien el individualismo surgido en occidente ha sido la causa de un desarrollo tecnológico generador indirectamente de grandes bienes sociales, se transformado en la actualidad en un hiperindividualismo que lleva a la pérdida de valores como la solidaridad con los demás. En este sentido, Morin nos enfrenta a una cruda conclusión: ${ }^{31}$ a un sistema que no es capaz de resolver los problemas que encuentra sólo le queda morir y crear un metasistema - un sistema más rico y poderoso a través de una metamorfosis -.

Efectivamente, la originalidad de la vida deriva, no de su substancia, sino de la complejidad de su organización, que es una autoorganización. Morin apuesta, pues, decididamente por una metamorfosis; para lograrla apela directamente a unas virtudes bien conocidas por todos: la fe en que lo improbable puede producirse - por supuesto, la máxima probabilidad la tiene la autoaniquilación del planeta por intervención humana -, y un nuevo evangelio, no de la salvación, sino de la perdición, es decir, un evangelio de la fraternidad "negativa": puesto que todos nos perderemos, todos moriremos, seamos hermanos. Perdidos en el vasto universo, el mismo sentimiento de estar perdidos nos impulsa a concentrarnos en nuestro destino de habitantes de la tierra. Aunque parezca paradójico, la idea de Morin se concreta en actitudes humanas muy habituales: la sensación de estar perdidos suele estimular a "abrirnos" al entorno y a la gente, a sentir la interdependencia mutua. La respuesta a la muerte es, entonces, el amor al sentirnos copartícipes de la vida.

Finalmente, Edgar Morin comenta el papel que deberían tener las diversas religiones. ${ }^{32}$ Las religiones deberían ser capaces de unirse bajo el denominador común de: la universalidad, la solidaridad, la caridad - en el sentido profundo de "virtud", en tanto que viene del corazón - y la compasión.

\footnotetext{
${ }^{30}$ Morin, Edgar: Opus cit., Pág. 66-67

${ }^{31}$ Ibid., Pág. 76-77

${ }^{32}$ Ibid, Pág. 94
} 


\section{La estética en tiempos de crisis}

\section{La crítica adorniana}

No abundan los filósofos que conozcan de cerca la música, Adorno es una excepción. No solamente como el musicólogo que era, sino como el mismo se definía: " un filósofo acostumbrado a pensar con los oídos". ${ }^{33}$

Éste es un punto importante que no deberíamos pasar por alto: la perspectiva estética no afecta solamente a cuestiones relacionadas exclusivamente con el gusto, sino que condiciona la forma de estar en el mundo y la forma de pensar. Desgraciadamente, Adorno murió precisamente cuando se iniciaba la vanguardia musical posterior a la Segunda Escuela de Viena Schoenberg, Berg, Webern -. A pesar de ello, sus intuiciones sobre la música y el arte futuro son de una extrema lucidez y pueden servir perfectamente de base para una crítica posterior - desde la perspectiva, sin embargo, propia de una época de moralización e, incluso, de politización del arte en que vivió el filósofo alemán, en franco contraste con el actual "todo vale".

Adorno parte de la concepción weberniana de la historia, concibiendo el arte musical como un dominio del material sonoro y del proceso de racionalización de su mundo. A partir del metarrelato de la Ilustración, ve precisamente en el clasicismo vienés el desarrollo de la racionalidad unida a los ideales de la Revolución: libertad, igualdad y fraternidad. No obstante, contempla en el Beethoven de su última época precisamente el comienzo del fin de este proyecto de humanidad. La música, a partir de entonces buscará el camino del grito de la humanidad oprimida, que nos conducirá al mundo despiadado del siglo XX - Un superviviente de Varsovia de Arnold Shoenberg representa la culminación de este movimiento -.

En contraposición a los antiguos maestros Bach y Beethoven, que hacían una música comunicativa, la nueva música niega la comunicación. Escribe Adorno, en su Teoría estética: "el arte nuevo trabaja en la transformación del lenguaje comunicativo en uno de mimético". ${ }^{34}$ Lo que en Beethoven o Schubert eran obras destinadas a afirmar la humanidad, en la nueva música ha devenido negación crítica.

Para Adorno, en un mundo de horror la música ya no puede continuar dando placer, sino absurdo y espanto, sobrepasando la inhumanidad del mundo por amor al hombre. ${ }^{35}$ Más allá del lenguaje del sufrimiento, sólo queda el camino

\footnotetext{
33 Adorno, Theodor W.: Prismas, Ariel, Barcelona, 1962. Pág. 9

${ }^{34}$ Adorno, Theodor W.: Teoría Estética, Taurus, Ediciones, Madrid, 1971. Pág. 151

${ }^{35}$ Adorno, Theodor W.: Filosofía de la nueva música, Sur, Buenos Aires, 1966. Pág. 104 y ss.
} 
del neoclasicismo o de las músicas de entretenimiento planificadas desde los intereses de la industria del ocio.

¿Qué papel le queda, pues, por hacer al artista? En su Filosofía de la nueva música, Adorno señala que: "en virtud de la antítesis frente a la sociedad, (el artista) conserva una verdad social, gracias al aislamiento: pero precisamente eso, a la larga, lo hace perecer". ${ }^{36}$ Esta actitud casi heroica del artista, tal como la describe Adorno, declinó de forma rápida en los últimos tiempos: "Hoy, artistas como Berg o Webern no tendrían ni la posibilidad de invernar en un escondrijo". ${ }^{37}$

De la vanguardia, incipiente en aquel momento, Adorno ya criticaba sus bases ideológicas: "El mismo proceso de composición es finalmente fiscalizado: los diagramas substituyen las notas, y las ecuaciones de sonidos producidos electrónicamente substituyen el acto de composición, que al final acaba pareciendo una arbitrariedad subjetiva" ${ }^{38}$. De aquí su denuncia a la "cosificación" perfecta de la música: lo que quiere ser pura naturaleza acaba siendo idéntico a lo puramente fabricado. Desde un punto de vista ontológico, esta absoluta dominación subjetiva de la naturaleza, como mero proceso técnico, da lugar a que el sujeto de la dominación absoluta se desposea de su humanidad, a la vez que se desconozca a si mismo: "El sueño de una música completamente espiritualizada, que ha dejado atrás el estigma de la animalidad del ser humano, despierta como rudo material prehumano y monotonía mortal". ${ }^{39}$

Para bien o para mal, la música, según Adorno, contiene en sí misma algo inaprehensible, caótico y mítico - dionisíaco -. De algún modo, la modernidad y el ideal de progreso de la ilustración es la "victoria" de la pintura sobre la música:"La música mira con ojos vacíos a quien la escucha". ${ }^{40}$ Sin embargo, la idea adorniana puede, a nuestro parecer, tomarse justamente en sentido contrario: el retorno al sentido dionisíaco que nos brinda la música puede ser una forma de vencer al espíritu de la modernidad que nos ha arrojado a la situación actual. Cuando uno se pregunta sobre qué es la música, la respuesta no está carente de riesgo: la esencia de la música consiste en una fugacidad que la expone a estar en peligro. Por eso, en una situación de peligro como la que vive la humanidad de hoy, la música nos devuelve la verdadera consciencia. En consecuencia, no es en absoluto baladí el papel de la música en el diagnóstico de la problemática social en cada momento histórico: el análisis del estado en que actualmente se encuentra la creación musical es algo fundamental para la comprensión filosófica

\footnotetext{
${ }^{36}$ Ibid. Pág. 24

${ }^{37}$ Ibid. Pág. 189

${ }^{38}$ Adorno, Theodor W.: Sobre Música, opus.cit. Pág. 35

${ }^{39}$ Ibid. Pág. 35

${ }^{40}$ Ibid. Pág. 69
} 
- como, a la inversa, el conocimiento de filosofía que se hace hoy no se debería separar de la situación actual del arte musical -.

La relación de la música con la historia es indiscutible para Adorno: sin historia, la música no tendría esencia: la música no es ser, sino " un devenir, y en tanto que devenir humano un comportarse". ${ }^{41}$ Por eso, la crisis de sentido que intuye Adorno en las artes de vanguardia es una aproximación de éstas a una realidad extra-estética: la pintura se aproxima cada vez más desde el punto de vista estructural a la música, mientras la música se torna gráfica en la notación de Stockhausen, Boulez, etc... Ello significa, a fin de cuentas, un tratamiento de la realidad como algo distante, extraño y cósico, pero muy cercano a la realidad virtual de les artes digitalizadas actuales, que Adorno no pudo conocer.

La clave para comprender el mensaje adorniano referido al papel trascendente de la música está en el concepto de historicidad. Adorno distingue dos tipos de historicidad: una historicidad externa y otra interna. No es que la música posea principalmente historicidad interna, sino que la historicidad interna de la música, el tiempo inmanente, es el tiempo histórico real, reflejado como apariencia. Se trataría, pues, de un "tiempo de calidad" - tal como hemos argumentado al tratar de la ética en la contemporaneidad -, tiempo éste sin el que no es posible es despliegue completo de la experiencia estética en toda su riqueza y complejidad. Es el tempo: el tempo que la música despliega a través de su historicidad interna. De ahí se desprende la importancia que toma la música en el pensamiento estético y filosófico en general.

A todo ello ¿cómo responde la sociedad en su conjunto, en su mayoría estadística?

\section{El espíritu de la música "ligera"}

Las preocupaciones de Adorno que en su tiempo le inspiró el nacimiento de las nuevas vanguardias de la década de los sesenta, a ojos y a oídos de la crítica realizada en los albores de la segunda década del siglo XXI, han pasado totalmente eclipsadas por el enorme alud de productos y subproductos lanzados al mercado por la industria del ocio y del espectáculo. Las "vanguardias" han quedado reducidas a meras "manías" vacías de contenido de una élite intelectual endogámica y plagada de puro esnobismo. El divorcio entre público y compositor se ha consolidado definitivamente, y el arte contemporáneo, pálido y escuálido frente a la lozanía en la que el mercado mantiene al producto estúpido, tiempo ha que inició su vergonzosa retirada, no sin carroñar, cuando así se tercia, sagaz y disimuladamente - no sea que por esto el artista despierte la voracidad

\footnotetext{
${ }^{41}$ Ibid. Pág. 69
} 
envidiosa de algún colega descolgado - las migas que con displicencia adjudica el "responsable" de cultura de la administración de turno mediante su "política" de subvenciones, bendecida, eso sí, por los sempiternos mandarines del ramo.

Mientras tanto, niños y adolescentes han crecido durante décadas educados en el relativismo estético del "todo vale", lo que ha propiciado un embrollo mental de proporciones gigantescas en el que tiene cabida en el mismo registro musical los nombres de "Liszt, Lola Flores y Lady Gaga", sin que este despropósito haga sonrojar hoy en día a nadie.

Sin embargo, el todovalismo no es nada más que la consecuencia de la pérdida de la experiencia del "tiempo de calidad" precisamente en aquel arte que desde siempre nos ha rescatado de la impropiedad a la que fue arrojado desde el principio el individuo moderno: el arte de la música. ¿Con qué se salará, pues, esta "sal" del espíritu? ¿Cómo se puede "musicalizar" de nuevo la música para que llegue a recuperar su tiempo, más allá de su historicidad interna o externa?

Henos aquí ante un auténtico fenómeno de masas predominante entre la población. En términos técnicos musicales lo defino como la estética de la anticipación sincopada. ¿En qué consiste?: mientras que la anticipación "del tiempo de calidad" enfatiza la llegada del presente que está apunto de llegar, esta anticipación sincopada - fácilmente identificable en cualquier ritmo con swing, omnipresente en cualquier producto de la industria musical - subraya exageradamente la preparación, la incitación y el deseo de realidad, a la vez que, paradójicamente, suprime la realidad justo en el mismo momento de presentarse. La anticipación sincopada hace de la incitación o el deseo el objetivo en si de la experiencia, secuestrando el presente, anticipándolo para luego poder suprimirlo. No se acepta la realidad presente sino que se obliga a satisfacerse en la virtualidad, sin la presencia real de las cosas. Hace de la promesa un objetivo definitivo. Una enorme tachadura encima de la realidad y de la vida.

¿Qué clase de horror motiva a ello?

\section{Ética y estética: confluencia superadora en la paradoja}

\section{La paradoja de los sentimientos "ajenos": la com-pasión}

Muchas veces, la igualdad y la fraternidad llegan a confundirse en un vago sentimiento de piedad o de caridad para los más desfavorecidos. Como decía Adorno, el arte se ha de poner del lado del que sufre. ${ }^{42}$ Por otra parte, Deleuze en su Lógica de la sensación, al describir la "pieza de carne" que pinta Francis

\footnotetext{
${ }^{42}$ Vilar, Gerard: Introducción de Sobre música, opus cit.. Pág.13
} 
Bacon, afirma que el artista simboliza una igualdad fundamental entre el animal y el hombre: el animal-pieza-de-carne se convierte en hombre como el hombrepieza-de-carne se torna animal. ${ }^{43}$ En este orden de cosas, ¿hasta que punto la separación entre la carne y los huesos no simboliza el drama entre la concepción del mundo que nos propone el arte y el que propone la ciencia-tecnología, o entre intuición artística y razón científica?

Como consecuencia de los atroces atentados terroristas con los que macabramente se inauguró el nuevo milenio - muy especialmente, por su proximidad, el del 11-M en Madrid - somaticé una serie de emociones y sentimientos profundos de dolor, de vergüenza y de culpabilidad - sorprendente para mí ésta última, puesto que no tenía ninguna relación con los presuntos autores del atentado, y me sentía totalmente solidario con las víctimas -. Posteriormente, al hacer una introspección en estos sentimientos, llegue al final a la conclusión que eran sentimientos derivados que tenían como base un sentimiento todavía más profundo: la compasión. Com-pasión en absoluto entendida como habitualmente se siente, como sentimiento de lástima y condolencia por las víctimas, sino principalmente - aunque esto puede parecer extraño y sin excluir en modo alguno el sentimiento de piedad hacia las víctimas - por los verdugos. Constaté que lo que el asesino, el criminal terrorista se obliga el mismo a no expresar - vergüenza, culpabilidad, dolor por el mal producido...-, lo sentía espontáneamente yo por ellos a través de la compasión.

Por ello, me atrevo a decir que la compasión es el fundamento auténtico de toda actitud ética. Hermanada con el "sentido común", la "vergüenza ajena", etc., la compasión manifiesta el sentimiento común del alma colectiva; es decir, la del ente social por encima de la cualquier problemática personal - sin que ello nos impida el ejercicio de las necesarias acciónes preventivas o la intervención procesal de la justicia sobre los delincuentes-. Pero, sin compasión no puede haber autoridad moral, puesto que es lo que hace posible la superioridad ética que nos sitúa más allá de la bipolaridad "buenos y malos", "víctimas y asesinos". Creo que debería considerarse un error, si bien totalmente comprensible, situarse en defensa de las víctimas desde el mismo sentimiento de odio que ha inspirado a los criminales. A mi modo de ver, la única manera de mantener unida el alma colectiva - en el sentido de fraternidad que apuntábamos anteriormente -, a pesar de los terribles cánceres sociales, las heridas que nunca cicatrizan, la esclerosis del fanatismo estúpido e insensato, es compadecerse de los malvados, de los enemigos declarados de uno mismo y del pueblo: cargar con el peso de su vergüenza y su culpa y, si es necesario y a pesar de lo escandaloso que significa, pagar su deuda inaceptable.

\footnotetext{
${ }^{43}$ Deleuze, Gilles: Francis Bacon. Lógica de la sensación, Arena libros, Madrid, 2002. Pág. 33
} 
No cabe duda que los sentimientos ajenos son realmente misteriosos: la vergüenza ajena, el pudor ajeno frente al comportamiento impúdico del otro, bien podrían definirse como la matriz de los sentimientos sociales o intersubjetivos. Porque la responsabilidad o la culpabilidad frente a una acción propia acaba en mi mismo, pero la culpa ajena me supera y me desborda, produciendo en mi una catarsis en si reconciliadora y, en consecuencia, regeneradora de los vínculos sociales.

Es necesario, pues, aprender a pedir disculpas no sólo por nosotros, sino también en nombre de aquellos que son incapaces de pedirlas. Es necesario aprender a llorar aquellas lágrimas que nunca derramaron ni derramaran los verdugos. ¿Donde se encuentra, entonces, el ego del hombre compasivo?: cuando la compasión mueve la culpabilidad ajena a superar incluso la legítima reacción natural frente al propio dolor y a la propia indignación, entonces el ego se eclipsa y se manifiesta con toda su pureza la identidad colectiva, el nos.

La compasión es pues una llamada a superar el egoísmo, incluso el más legítimo. ¿Cuál debería ser, por ejemplo, la actitud colectiva más legítima frente a los horrores de Auschwitz?: lo que nos hace sentir auténtica piedad no es la asunción del papel de las víctimas - ésta es una actitud legítima que fácilmente puede llegar a confundirse e identificarse con la de aquel que teme que algún día pueda acabar siendo una de ellas -, sino porque asumimos la enorme vergüenza y culpabilidad de aquellos criminales que jamás las sintieron.

A mi entender, si algún día perdiésemos la capacidad de experimentar los sentimientos "ajenos", la humanidad en tanto alma colectiva quedaría rota definitivamente para siempre. En este sentido, la educación de los sentimientos es imprescindible para la formación de la personalidad de los niños y adolescentes, y debería ser materia obligada en la escuela.

\section{La paradoja de la expresión "ajena": la escucha silenciosa}

Desde el momento que comprendo la expresión del otro, mi cuerpo y mi campo intelectual y afectivo la asimilan como algo mío. Tanto la expresión del otro como su proceso de asimilación por mi parte requieren un tiempo adecuado a ambas. Cuando no se presenta este tiempo de calidad aparece la torpeza expresiva y la escucha intermitente que llevan a la palabra, a la acción a aparecer a des-tiempo; a veces con retraso y otras con anticipación, nunca $a$ Tempo, y menos todavía a Tempo Giusto - con gracia, elegancia y estilo -. Aparece entonces la sordera en sus múltiples facetas.

Y no es la sordera propiamente física la más problemática sino la sordera que llamaremos intencional: la sordera $a$ y la sordera para determinados 
aspectos del mundo exterior o interior de la persona. Se trata, pues, no de una falta de audición sino de una sordera de la escucha.

Con esto, no quiero decir que no pueda existir un daño físico directo sobre el oído debido a la violencia de los ruidos a los que estamos cada vez más expuestos: el mundo se ha vuelto cada vez más ruidoso, y el mal uso de la tecnología no puede esconder aquí su grave responsabilidad. Existe un problema de contaminación acústica que representa un ataque brutal a la sensibilidad y que tiene sus efectos y consecuencias no sólo en los sentidos físicos. No obstante lo dicho, nos encontramos con sorderas aún más profundas: la sordera del corazón y la del sentido.

La sordera del corazón impide sentir las emociones, las pasiones y los sentimientos propios y ajenos. Aparece, así, la desconexión con el propio cuerpo, viviéndose todo desde una "virtualidad" irreal y opaca. La voz del otro nos llega como un sonido descarnado desde una impostura rígida de indiferencia que nos hace no sólo palidecer, sino también, lo que es peor aún, enmudecer.

En paralelo a la sordera del corazón, aparece una sordera del sentido: una incapacidad para comprender que arroja a su víctima a la incapacidad para el gusto estético. Lo mediocre hace acto de presencia y se instala en el individuo. Se ha perdido así la solicitud, la atención a lo que expresa el otro y a sus valores, porque antes se ha dejado de prestar atención a uno mismo y a los valores propios. La vida se ha vuelto gris. El rostro del otro se ha desdibujado y aparece ante nosotros rodeado de una especie de neblina, de una borrosidad anónima.

¿Cómo recuperar, pues, la escucha en medio de este océano acústico tan sumamente contaminado? ¿Es todavía posible devolver el sentido perdido a unas palabras que han quedado tristemente resecas, escuálidas, barridas por la catástrofe "ecológica" provocada por aquello que las ensordece?

El camino para una re-construcción de la escucha pasa por una previa construcción estética del oído y por una necesaria ascesis, para podernos desprender de la falsa escucha que no atiende a nada ni a nadie. Paradójicamente, el instrumento básico que nos ayudará a la realizar este camino será aprender a prestar atención al silencio.

La atención al silencio orienta nuestra percepción a la sensación temporal en estado puro, abriendo nuestra sensibilidad - y no sólo la auditiva - en toda su profundidad. En este sentido, la apertura al silencio es experimentada también como una sensación estética: si el ruido nos arrastra a la sordera en cuanto pérdida de sensibilidad, la atención al silencio nos puede devolver la capacidad de escuchar la "música" del mundo, su tempo, su movimiento espontáneo y el sentido auténtico de la temporalidad.

Porque en la escucha silenciosa experimentamos el verdadero movimiento del tiempo, su fluir originario. Es entonces cuando el tiempo deja de ser para 
nosotros un mero "marco" de acontecimientos o un "contenedor" de cosas que se mueven para su medida, control y clasificación, y recuperamos el tiempo como pura movilidad.

¡Qué lejos se encuentra este movimiento del concepto moderno de velocidad que hoy todo lo inunda y que disuelve el carácter que acompaña al movimiento y al ritmo! Entonces es cuando nos damos cuenta que por muy veloz que uno se mueva, por muy rápido que sucedan las cosas, todo permanece inalterado en el fondo porque no ha habido tiempo para el verdadero cambio. Éste sólo aparece cuando existe tiempo; y tiempo de calidad.

\section{Conclusiones generales}

La argumentación sostenida a lo largo de este escrito, a nuestro entender, avalan nuestra tesis de que no es posible un espacio para la ética sin un tiempo para la estética.

Por una parte, la apertura de un espacio para la ética - desaparecida para una humanidad en crisis -, por angosto y minúsculo que parezca, pasa por la asunción de los sentimientos ajenos y la in-corporación - en el sentido genuino de formar parte del cuerpo orgánico - de la compasión de aquellos que no la sienten. Sentir vergüenza ajena es la manifestación más evidente de la existencia de un vínculo social incluso entre aquellos que quieren romperlo definitivamente.

Por otro lado, hemos puesto de relieve que la razón de ser de esta insensibilidad hacia lo humano radica en lo que hemos venido a calificar de sordera en sus diversas manifestaciones. Sordera que impide vivir el tiempo de calidad, sin el que no es posible la experiencia estética. Sólo a través de una escucha atenta al silencio será posible inaugurar un tiempo para la estética, un verdadero tempo, que a la vez nos permita comprender al otro, reconocer su voz y mirar su rostro.

En definitiva, la paradoja del sentimiento ajeno - el sentimiento de lo insentible en mi - y la de la escucha al silencio - la escucha de lo inaudible para mi - han mostrado ser vías para romper las inercias sistémicas que nos arrojan al vacio individual y colectivo. Vacío que, previo análisis, nos ha llevado a confirmar en el escenario de la contemporaneidad, en primer lugar, la imposibilidad de unas condiciones que hagan viable una ética heredera de la modernidad - más allá de la "fraternidad" post-mortem que parece asomarse en el pensamiento de algunos de los autores a los que nos hemos referido - y, posteriormente, el triunfo de una inhumanidad fabricada "industrialmente" y que aturde cualquier atisbo de sentido de lo estético. 
Se abre así un nuevo espacio y un nuevo tiempo. Un territorio nuevo para lo ético y para lo estético. Nuevos, por lo que tienen de sorprendentes respecto de un mundo que se ha vuelto viejo a toda velocidad. Demasiado viejo.

\section{Un reto para la praxis filosófica}

Esta es la situación que se abre ante el filósofo de hoy. Este es el marco ineludible que no debe ignorar quien se pregunta por los problemas sociales e individuales que nos acucian. La filosofía llevada a la praxis está obligada a contemporizar con la facticidad histórica y las singularidades irrepetibles de su tiempo y de sus circunstancias. De nada serviría hacer el ejercicio de abstracción que supondría trasladar virtualmente la problemática de tiempos pasados al nuestro y, menos aún, buscar en las preguntas y respuestas formuladas antaño, posibles modelos o protocolos de actuación para hoy o mañana: la singularidad de nuestro tiempo, en mi modesta opinión, hace imposible el "reciclaje".

El reto para la praxis filosófica consiste en llegar a encontrar lugares comunes que unan y puedan ser plenamente compartidos por todos, a pesar de lo catastrófica que pueda llegar a ser la coyuntura dada y aun en la tesitura más violenta y corrosiva en lo social en la que uno pueda estar inmerso. Hoy, no serán las creencias ni las ideologías las que vendrán a socorrer y a tomar cuidado del individuo y del colectivo, sino más bien la existencia encubierta de hondos sentimientos que, en tanto que humanos, necesariamente compartimos. En la medida en que estos sentimientos sean revividos y valorados nuevamente, aunque existan estructuras e individuos que se opongan expresa o tácitamente a ellos, hay motivo para la esperanza.

Para este propósito viene también a ayudarnos el sentimiento estético que habla directo al corazón, y que aparece especialmente en el arte y muy singularmente en la música. Por eso es tan importante que se abra y se preserve con sumo cuidado un tiempo para la estética; un tiempo en el que pueda darse la experiencia del sentimiento estético y, en consecuencia, quede accesible el camino a los sentimientos genuinos que la coyuntura actual suele obstaculizar. De esta necesidad surge una nueva praxis filosófica: la Pràctica filo-musical. ${ }^{44}$

\footnotetext{
${ }^{44}$ El contenido y los objetivos de la Pràtica filo-musical aparecen concretados en la tesina del Master de Práctica filosófica y gestión social de la Universidad de Barcelona que elaboré con el título "Introducción a la Práctica filo-musical. La experiencia musical en la práctica filosófica" (Barcelona, 2008). Previo a este trabajo redacté la ponencia Oh, Socrates! Make and cultivate music para la IX ${ }^{\mathrm{a}}$ Conferencia Internacional sobre Práctica Filosófica (Italia, 2008), en la ya quedan esbozados algunos de los contenidos más importantes de esta praxis. En paralelo a esta labor, la redacción de mi tesis doctoral La estética musical como Prima Philosophia supuso para mí un trabajo de profundización
} 
En esta disciplina se parte del reconocimiento de la irreductibilidad de la vida emocional a la pura racionalidad, haciendo de ésta una derivada de la vida anímica, en la que el fenómeno que llamo sentimiento estético - que está en la base de todas las manifestaciones artísticas - resulta ser el paradigma de los sentimientos, emociones y pasiones universales que experimentamos en nuestro vivir cotidiano. Este sentimiento estético se presenta en su esencia más pura en la experiencia musical en general y, en particular en su escucha. Abrirse al sentimiento estético es de suma importancia para reconocer y contactar con las diversas cosmovisiones de cada sociedad y cada persona, para cada tiempo y cada cultura.

Los problemas anclados en el campo afectivo suelen tener su origen en la calidad de la vida emocional de las personas, la cual, a su vez depende de cómo han sabido éstas expresarla en sus diversas experiencias vitales y integrarla en su personalidad. El objetivo de trabajo concreto de asesoramiento filo-musical consistirá, en primer lugar, en ayudar a limpiar y empezar a poner orden a su campo afectivo. Para ello es necesario llegar a la sublimación del caos emocional en el que pueda vivir el individuo.

¿Qué significado adquiere la palabra "sublimación" en el contexto de la praxis filo-musical? No se trata en absoluto de agenciarse el concepto homónimo proveniente del psicoanálisis. Para nosotros la sublimación significa trasladar al lugar que corresponde, a su propio lugar de origen, lo que ha sido des-plazado en relación a los sentimientos. En el mismo instante en que logramos resituar los sentimientos, vivirlos desde su fuente, se realiza en el individuo la liberación de las circunstancias que en su día se asociaron a ellos, lo que sólo ha servido hasta entonces de causa de malestar. De esta manera conseguimos desdramatizar y disolver la vivencia que había "cristalizado mal" en la personalidad del individuo, a la vez que ayudamos a ésta a centrarse. Es lo que hemos venido argumentando al hablar de la terrible experiencia de la violencia terrorista: el conglomerado de emociones, de estímulos sensoriales, de pensamientos que se despiertan ante tamaña experiencia cristaliza en algo que desborda las estructuras mentales y emocionales del individuo. En este caso es la revelación de la compasión y la toma de conciencia de los sentimientos ajenos, las que abren el camino para una posible sublimación.

sobre el sentimiento estético que ha ayudado a fundamentar todavía mejor las ideas y la estructuración de la Pràtica filo-musical. Posteriormente, en cursos de formación organizados por la AFPC (Asociació de Filosofia Pràctica de Catalunya) y en mi comunicación para el I Congreso de ámbito español de Filosofía Práctica o Aplicada celebrado en Barcelona en 2011 (recogida en un capítulo del libro Intervenciones filosóficas en la sociedad. Visión Libros. Madrid 2011), ha quedado, a mi entender, cada vez mejor explicitada la temática aplicada a casos concretos. 
Sin embargo, el camino a la sublimación de las experiencias choca de frente con la insensibilidad que las sociedades posmodernas explícita o implícitamente promueven. Aparece la sordera no sólo física, como hemos tenido ocasión de explicar, sino la del alma. El otro aparece frente a nosotros como un objeto opaco que da señales inconexas e intermitentes, llenas de lagunas, de vacios que intentamos compensar con nuestros prejuicios y nuestras más arbitrarias hipótesis "personales".

A partir de aquí se dibuja un nuevo eje o pilar de la praxis musical: la escucha. Efectivamente, la práctica filo-musical nos invita a aprender a escuchar desde la tríada cuerpo, corazón y espíritu en perfecta armonía, tal como se hace en la escucha musical atenta, para poder extrapolarlo al ámbito de la cotidianidad: debemos aprender a escuchar al otro con los sentidos, con el corazón y con el espíritu. Así logro no sólo comprenderme a mí y comprender al otro, sino también comprender al otro en mí y a mí en el otro.

En definitiva, el objetivo último de toda praxis filosófica es llegar a la comprensión del mundo y de si mismo (autocomprensión) por parte de cada individuo, colectivo o sociedad. Que esta comprensión y autocompresión nos conduzcan posteriormente a una actitud de rebelión, de aceptación o de resignación (por poner unas cuantas actitudes posibles) dependerá en último término del ejercicio de la libertad personal o colectiva. Pero no se puede ejercer la libertad allí donde impera la ignorancia de nosotros mismos y de nuestras circunstancias.

\section{Bibliografía}

Adorno, TheOdor W.: Filosofía de la nueva música, Sur, Buenos Aires, 1996. Teoría estética. Taurus, Ediciones. Madrid, 1971.

Musikalische Schriften, Vol. II, III i V. Suhrkamp Verlag, Francfort, 1984.

Prismas. Ariel. Barcelona 1962

BAUDRILlARD, JEAN: La violencia de lo mundial, Paidós, Barcelona, 2004.

Olvidar a Foucault, Pre-textos, Valencia, 1986

Beethoven, Ludwig van: Complete String Quartets, Dover Publications Inc., New York, 1970

Benjamin, Walter: La dialéctica en suspenso, Arcis-Lom Ediciones, Santiago de Chile, 1996

BOURDIEU, Pierre: La distinción, Taurus, Madrid, 1998

DeLEUZE, GILles: Francis Bacon. Lógica de la sensación, Arena libros, Madrid, 2002. 
DERRIDA, JACQUES: La différance, Bulletin de la Societé française de philosophie (julio-septiembre, 1968).

Durkheim, Émile: La división del trabajo social. Ediciones Akal. Madrid 1987 El suicidio. Ediciones Akal. Madrid 1982.

FouCAUlT, MichEL: Vigilar y castigar. Siglo XXI. México. 1977.

HEIDEGGER, MARTIN; El ser y el tiempo, Fondo de cultura económica, México, 1951.

KERST, Friedrich: Beethoven: the Man and the Artist, as Revealed in his own Words, H.KREHBIEL (Editor), The Project Gutenberg EBook of Beethoven.

LASH, Scott: Sociology of Postmodernism, Routledge, London, New York, 1990

LYON, DAVID: Posmodernidad, Alianza Editorial, Madrid, 2000.

LYOTARD. FRANÇOIS: La condicion posmoderna, Cátedra, Madrid, 1984.

MORIN, EDGAR: En el corazón de la crisis planetaria, Paidós, Barcelona, 2004.

SCOTT, Marion M: Beethoven, Salvat editors, Barcelona, 1985.

VATTIMO, GiAnNI: El fin de la modernidad, Gedisa, Barcelona, 1986. 